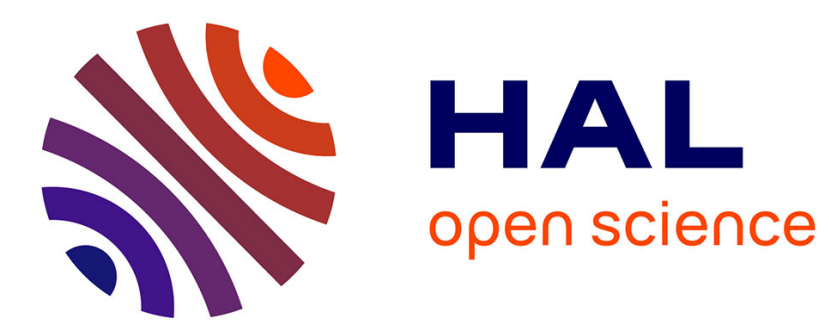

\title{
On geometric focusing of hydrogen negative ions in the surface-plasma sources
}

\author{
Yu. I. Belchenko, A.S. Kupriyanov
}

\section{To cite this version:}

Yu. I. Belchenko, A.S. Kupriyanov. On geometric focusing of hydrogen negative ions in the surface-plasma sources. Revue de Physique Appliquée, 1988, 23 (12), pp.1885-1888. 10.1051/rphysap:0198800230120188500 . jpa-00246017

\section{HAL Id: jpa-00246017 https://hal.science/jpa-00246017}

Submitted on 1 Jan 1988

HAL is a multi-disciplinary open access archive for the deposit and dissemination of scientific research documents, whether they are published or not. The documents may come from teaching and research institutions in France or abroad, or from public or private research centers.
L'archive ouverte pluridisciplinaire HAL, est destinée au dépôt et à la diffusion de documents scientifiques de niveau recherche, publiés ou non, émanant des établissements d'enseignement et de recherche français ou étrangers, des laboratoires publics ou privés. 


\title{
On geometric focusing of hydrogen negative ions in the surface-plasma sources
}

\author{
Yu. I. Belchenko and A. S. Kupriyanov \\ Institute of Nuclear Physics, 630090, Novosibirsk, U.S.S.R. \\ (Reçu le 3 mars 1988, révisé le 18 juillet, accepté le 23 août 1988)
}

Résumé. - Une analyse détaillée du rendement de la focalisation géométrique dans les sources plasmasurface est présentée.

Abstract. - A detailed analysis of the efficiency of geometric focusing in surface-plasma sources is presented.

The Geometric Focusing (GF) of charged particles, emitted by concave surface and post-accelerated to a focus point by the near-electrode potential drop is widely used in emission electronics. Attempts were made to use the GF for increasing the negative ion (NI) yield from earlier versions of surfaceplasma sources (SPS) [1]. The GF was experimentally demonstrated with a grooved cathode in the semiplanotron [2]. NI have effectively been focused from the grooved cathode surface of $3 \times 45 \mathrm{~mm}$ operation area to the narrow emission slit of $1 \times 40 \mathrm{~mm}$. The two-dimensional GF of SPS $\mathrm{H}^{-}$ ions was realized from spherically-concaved indentations of a honeycomb cathode to multi-aperture system of small emission holes [3].

The GF is widely used in modern versions of SPS, but a detailed study of GF was not yet performed. The analysis of GF efficiency in SPS based on computer simulation and experimental results is given below.

Model description. The modelling was performed for SPS with the planar, cylindrical and sphericallyconcave cathodes under the following general assumptions.

The NI emitter is the conditioned electrode with negative bias of 50-300 eV with respect to the plasma potential (Fig. 1). The plasma boundary follows the flat or concave emitter surface. The plasma-electrode gap, $\delta$, which depends on the discharge current density and transverse magnetic field, is small.

NI emission is caused by NI fraction of hydrogen particles, sputtered from selvage, or by direct conversion of fast hydrogen positive ion flux to emitter.

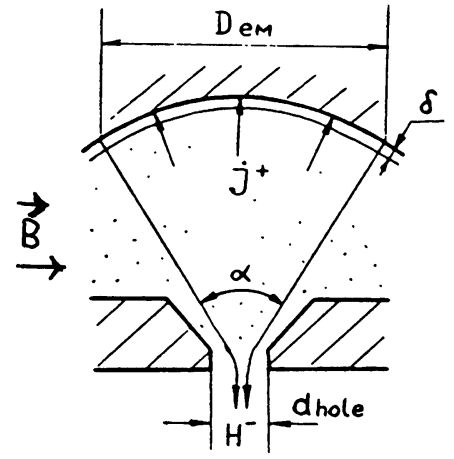

Fig. 1. - Geometric focusing scheme for negative ions into emission hole or slit. $\alpha$-the collecting angle.

The hydrogen positive ions $\mathrm{H}^{+}, \mathrm{H}_{2}^{+}, \mathrm{H}_{3}^{+}$were supposed to be accelerated by the near-emitter potential drop $U_{\mathrm{e}}$ and to hit the emitter normally to the surface. The ions $\mathrm{H}_{2}^{+}, \mathrm{H}_{3}^{+}$dissociate into particles having an energy of $1 / 2$ or $1 / 3$ of the initial energy when hitting the surface, so the double or triple amount of nucleons continue to run inside the target.

A special simulation code was developed using the principles of MARLOWE code [4]. The Monte-Carlo binary collision approximation was used with the Thomas-Fermi-Moliere potential.

The target was modelled as amorphous Molybdenum with trapped hydrogen concentration of up to $50 \%$. The binding hydrogen energy inside the target was supposed to be about $1.0 \mathrm{eV}$. The movement both of the primary and secondary particles in 
the target was recorded. The planar surface barrier for hydrogen was supposed to have the binding energy of $0.5 \mathrm{eV}$. It's value had low influence on negative ionization efficiency, especially for particles with small emission velocities [6].

The negative ionization degree for the emitted particles was supposed to be a product of NI formation probability and the NI survival probability. The $\mathrm{H}^{-}$ion formation probability for cesium coverage was calculated using a formula reported in reference [7], while the survival probability was calculated using a formula reported in reference [6]. The composed Cs-H coverage work function was supposed to be equal to $1.4 \mathrm{eV}$. The energy and angular parameters were recorded for the emitted NI. The NI post-acceleration by the near-emitter potential drop was taken into account by the corresponding increase in $\mathrm{H}^{-}$ion perpendicular velocity.

In such a way the SPS emission properties of planar, cylindrical and spherically-concave emitters were determined for various near-electrode potential drops and for various compositions of emitter positive ion current. The GF efficiency was calculated for various ratios between the emission hole and emitter surface area. The relative contribution of sputtering and reflection into SPS NI production was determined.

\section{Selected results.}

The calculated coefficients of complete reflection $K_{\mathrm{R}}=N_{\mathrm{R}} / N^{+}$and of absorbate sputtering $K_{\mathrm{S}}=N_{\mathrm{S}} / N^{+}$as well as calculated negative ion emission coefficient of reflection $K_{\mathrm{R}}^{-}=\frac{N_{\mathrm{R}}^{-}}{N^{+}}$and of absorbate sputtering $K_{\mathrm{S}}^{-}=N_{\mathrm{S}}^{-} / N^{+}$are given in figure 2 as a function of the bombarding proton energy for amorphous Molybdenum with $50 \%$ concentration of trapped hydrogen. With decreasing

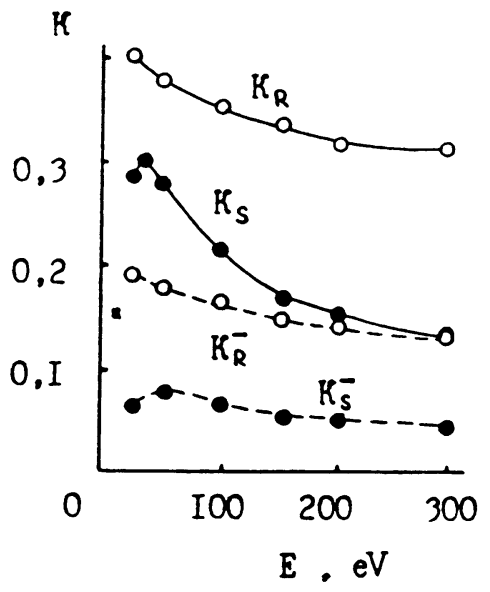

Fig. 2. - The simulated complete $K_{\mathrm{R}}, K_{\mathrm{S}}$ and negative ionisation $K_{\mathrm{R}}^{-}, K_{\mathrm{S}}^{-}$coefficients $v s$. primary particle energy.

proton energy the sputtering increases, but the coefficient $K_{\mathrm{S}}^{-}$has the temperate growth due to low sputtering particle energy. As a whole the calculated NI reflection $K_{\mathrm{R}}^{-}$exceeds the NI sputtering $K_{\mathrm{S}}^{-}$in a broad energy range of the primary particles.

The calculated energy and angular spectra of outgoing NI are given in figure 3 for primary particles with an energy of $100 \mathrm{eV}$. The energy spectra of NI reflected from hydrogen saturated selvage, contain a larger amount of particles in the 0.2-0.6 $E_{0}$ energy range ( $R$ in Fig. 3a), as compared with that for pure Molybdenum reflection. This amount increases with the growth of bombardment energy. The surface-reflected NI peak with high-energy $>0.9 E_{0}$ drops with bombardment energy growth.

The absorbate sputtering is mainly due to the returning flux of hydrogen particles reflected from interior of the target. The energy spectrum of sputtered NI consists of two groups (S in Fig. 3a). The high-energy tail with an energy of $\geq 10 \mathrm{eV}$ is
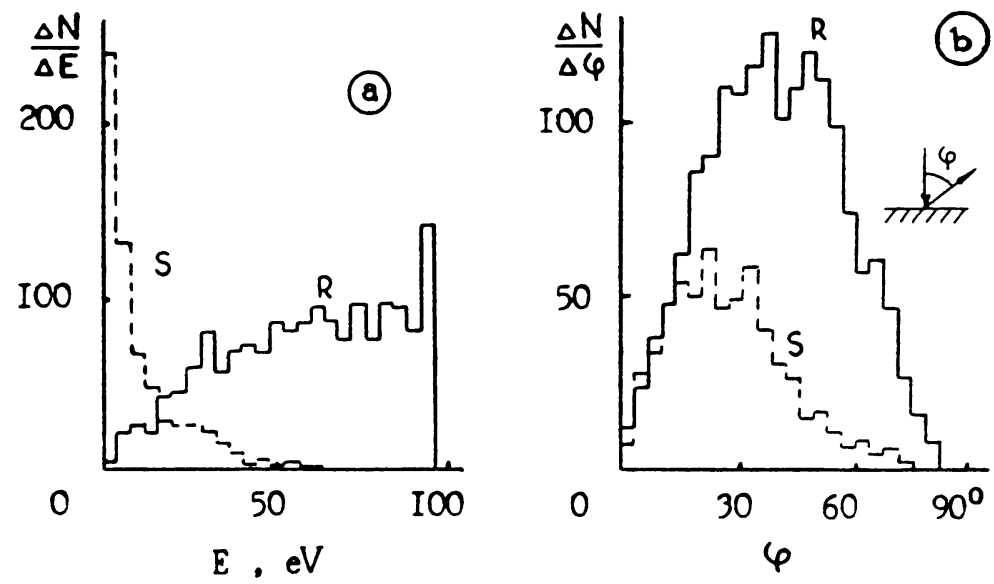

Fig. 3. - The energy (a) and angular (b) spectra of sputtered (S) and « reflected » (R) negative ions. The primary energy is of $100 \mathrm{eV}$. 
caused by sputtering from the interior of the target. The low-energy fraction consists of particles sputtered from the outer adsorbate layers. The highenergy tail increased with the bombardment energy growth.

The angular spectra of the emitted NI is given in figure $3 \mathrm{~b}$ ( $R$-reflected, $\mathrm{S}-\ll$ sputtered » NI). At higher exit angles NI distributions differed of cosine-law due to low NI survival probability at small emission velocities.

The normalized to the incident flux concave emitter $\mathrm{H}^{-}$yield through the small emission hole $Y_{\mathrm{H}^{-}}=N_{\text {exit }}^{-} / N_{\text {prim }}^{+}$is given in figure 4 as a function of the near-electrode potential drop for several types of bombarding ions. In the case of two-dimensional GF (GF-2) the positive ion conversion efficiency achieves $25 \%$ when the primary ions are $\mathrm{H}_{3}^{+}$.

The normalized yield dependence $v s$. relative emission hole $\mathrm{B}=S_{\text {hole }} / \mathrm{S}_{\mathrm{e}}=d^{2} / D^{2}$ is given in figure 5 for various species of primary ions with energy

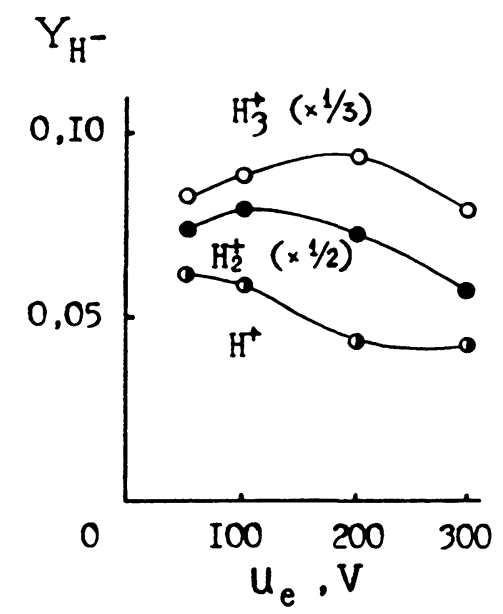

Fig. 4. - The calculated normalized $\mathrm{H}^{-}$yield vs. GF-2 emitter voltage, $\alpha=60^{\circ}, B=0.07$.

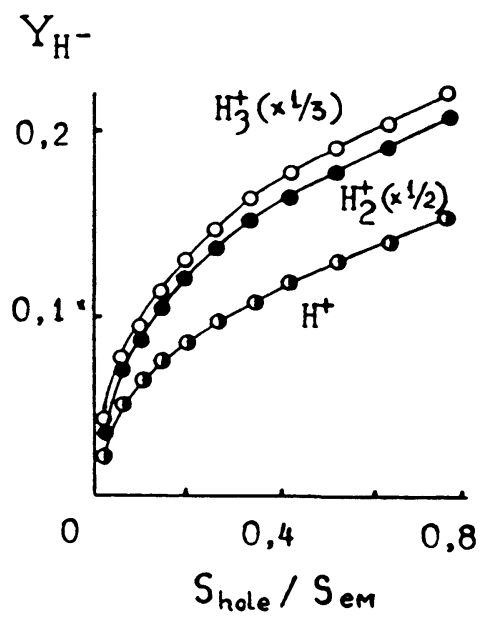

Fig. 5. - The calculated normalized $\mathrm{H}^{-}$-yield vs. GF-2 « relative » emission hole $\alpha=60^{\circ}$.

REVUE DE PHYSIQUE APPLIQUÉE. - T. 23, N` 12, DÉCEMBRE 1988 of $100 \mathrm{eV}$ in the GF-2 case. The calculated normalized NI conversion of $\mathrm{H}_{3}^{+}$achieves a value of about $25 \%$ for typical « relative » emission hole $B=0.06$ [3].

The ratio of sputtered NI fraction to reflected NI fraction $Y_{\mathrm{S}}^{-} / Y_{\mathrm{R}}^{-} v s$. relative emission hole dimensions is given in figure 6 for three types of incident ions with energy of $100 \mathrm{eV}$. In this GF-2 case and with $B=0.06$ the absorbate sputtered component exceeds by 2-3 times the reflected one.

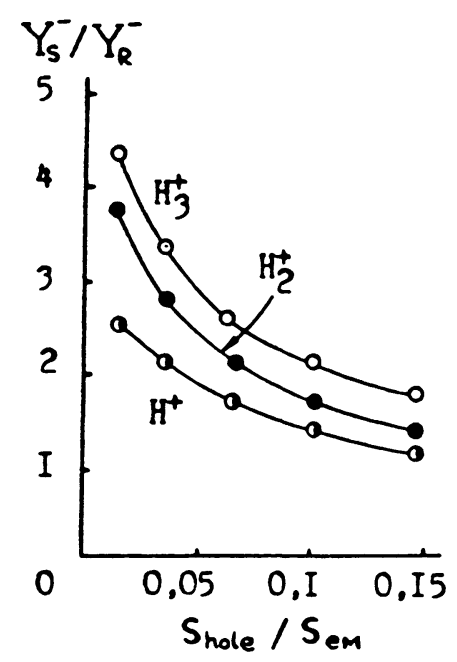

Fig. 6. - The simulated ratio of the sputtered and reflected NI fractions $v s$. "relative " emission hole for GF-2 $E_{0}=100 \mathrm{eV}, \alpha=60^{\circ}$.

\section{The GF efficiency of high-current SPS discharge.}

The GF efficiency of high-current SPS discharge is determined both by the near-electrode potential drop, the ion current composition, and by other factors such as emitter current density distribution, the near-electrode gap shape and thickness (Fig. 1), and the external magnetic field.

The experimental GF efficiency was revealed in the thin traces sputtered by heavy NI at the points of GF [3]. The trace diameter increased with the discharge current growth due to roughness of emitter surface. The low GF efficiency of SPS with independent plasma production and external transverse magnetic field can be caused by a plasma layer moving aside the emitter surface. The positive ion emitter current strongly decreased with emitter moving aside the magnetic field confined a plasma layer [8].

The comparison of the experimental $\mathrm{H}^{-}$yield from honeycomb SPS with that of the flat cathode SPS is given in figure 7. The GF efficiency decrease with discharge current increase is evidently caused by the change in current composition [8] and by roughness of concave emitter surface. The calcu- 


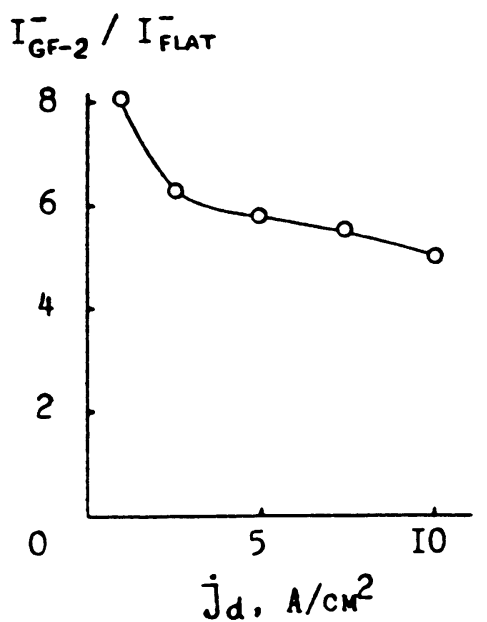

Fig. 7. - The experimental GF-2 efficiency vs. cathode discharge current density.

lated value $Y_{\overline{\mathrm{GF}}-2}^{-} / Y_{\text {flat }}^{-}$is equal to $8.7 \pm 0.1$ for the discharge current density $10 \mathrm{~A} / \mathrm{cm}^{2}, I_{\mathrm{H}^{+}}=I_{\mathrm{H}_{2}^{+}}=$ $I_{\mathrm{H}_{3}^{+}}, U_{\mathrm{e}}=100 \mathrm{~V}, S=0.06, \alpha=60^{\circ}$.

An intense primary ion flux and Frank-Condon hydrogen atoms with an energy of $1-2 \mathrm{eV}$ support the high dynamic density of hydrogen at the SPS emitters surface and selvage. The $\mathrm{Cs}^{+}$ion flux to SPS emitter helped to provide the vacancies and interstitials for trapping the hydrogen atoms with the binding energy increased up to $1-1.5 \mathrm{eV}$ [9].

The limited thermal diffusion of hydrogen atoms as well as the lowered due to Cs co-adsorption hydrogen thermodesorption can supply the high hydrogen concentration in the selvage of Moemitter under intense ion bombardment (higher than $50 \%-[11])$. The real structure and roughness of the surface increase the adsorption capacity and improve the NI sputtering.

\section{Conclusions.}

The increased trapped hydrogen concentration changes the target selvage response to particle-surface interaction. The energy losses of primaries increase, the incoming particles projected range in the target decrease, the energy spectrum of outgoing particles changes. The calculated reflection coefficient of particles is lowered with the trapped hydrogen concentration. The simulated coefficient of hydrogen absorbate sputtering achieves the value of 0.9 for a $50 \%$ concentration of trapped hydrogen and $\mathrm{H}_{3}^{+}$primaries with an energy of $100 \mathrm{eV}$. The intense sputtered NI flux with a relatively small energy $(5-10 \mathrm{eV})$ an angular $\left(\sim 10^{\circ}\right)$ spread is produced on hydrogen saturated emitters of SPS. The sputtered $\mathrm{H}^{-}$fraction predominates in NI-yield of GF-2 SPS.

\section{References}

[1] Belchenko, Yu. I., Dimov, G. I., Dudnikov, V. G., Izvestiya AN SSSR, Ser. Fiz. 37 (1973) 2573.

[2] Belchenko, Yu. I., Dudnikov, V. G., Preprint INP $\mathrm{N}^{\circ} 78-95$, Novosibirsk, 1978, also J. Phys. Colloq. France 40 (1979) C7-501.

[3] Belchenko, Yu. I., Fizika Plasmy 9 (1983) 1219.

[4] Belchenko, Yu. I., KupriYanov, A. S., Preprint INP $\mathrm{N}^{\circ} 88-16$ Novosibirsk (1988).

[5] Robinson, M. T. and Torrens, I. M., Phys. Rev. B 9 (1974) 5008.

[6] KishinevskiY, M. E., Soviet jour. tech. phys. 48 (1978) 773.
[7] Hiskes, J. R., Schneider, P. J., Phys. Rev. B 23 (1981) 949.

[8] Belchenko, Yu. I., Dimov, G. I., Dudnikov, V. G., in Proc. Symp. on production and neutralization of negative hydrogen ions and beams, Brookhaven, BNL-50727 (N.Y., 1977) p. 79.

[9] Bottiger, J., Picraux, S. T., RUD, N. and Laursen, T., J. Appl. Phys. 48 (1977) 920.

[10] Papageorgopoulos, C. A. and Chen, J. M., Surface Sci. 39 (1973) 283.

[11] Schulz, R., BeHrisCH, R. and Scherzer, B. M. U., Nucl. Instrum. Meth. 168 (1980) 295. 